\title{
Ten roles of teachers in Computer Assisted English Writing
}

\author{
$\mathrm{XU}$ Yiqun ${ }^{1, \text { a }}$ \\ 1 Jilin Business and Technology College, Changchun 130000, China \\ aemail: xuyiqun@163.com
}

Keywords: A variety of roles of the teacher; control; evaluation; Organizer; participant

\begin{abstract}
With the development of the times, the traditional teacher's single "control" role has been unable to meet the current needs of the development of education. Only acts as a lot of roles, to become a qualified teacher. This article describes the various roles of teachers, its role as well as the different roles should be paid attention to.
\end{abstract}

\section{Introduction}

With the rapid development of information technology and a variety of media, teacher is not for students to obtain knowledge and the only source, teachers and students is not the difference between the amount of knowledge, but the mental, emotional, personality, spirit and personality development in an all-round way. Therefore, the traditional teacher "preaching, tuition, FAQ" single "control" role is increasingly unable to meet the needs of the development of education.

Education is not a one-sided culture to teach, but to inspire people's creativity, the sense of life, values (emotional factors) to wake up, so that people can become a conscious, free activities of the people. (Pan Zhonggang, 2002)[1].

Education is changed from once and for all to lifelong learning, from collective to individual and individual, and the function of school is changed into knowledge by transferring knowledge. Teacher specialization is closely combined with the development of people, and the development of human changes with the changes of the times, these changes have higher requirements for teachers (Yu Shuyun, 2005).

The current our country's primary and secondary school English teaching by restricting the number of class and traditional education, many teachers just as "controller (controller)", "evaluation" (assessor) "and" organizer (organizer) ". And the ordinary high school English Curriculum Standard (Experiment) "clearly put forward the high school stage opened English courses not is to students who can speak a few foreign words, but rather to enable students to by learning English to promote mental, emotional, attitudes and values of development and integrated humanities increased quality of oxytocin." Teacher's role of "controller, organizer, and evaluation" is far from reaching the goal of the students. Therefore, the modern teacher in addition to ruminating over the role, also must be "participants (participant)", "teacher (tutor)", "the researchers (researcher)", "helper (helper)", "promoter (prompter)"[2].

\section{Controller}

"Control" is a very typical and traditional "Teacher centered" teacher role. Teachers complete control of the classroom -- not only to control what students do, but also to control when students say and use what English (Harmer, 1991).

This role has the advantage of explaining their attention to the teacher, and all students keep step with. Therefore, it is very effective in the introduction of new lessons and drills and other aspects of the sentence. But to really control every student, so they keep up with your teaching steps, the teacher's class must seize the attention of students and stimulate their interest. However, the role of the control of all the classroom, the students speak English very little time, is not conducive to the development of students' ability to use language. Therefore, teachers must provide students with the time and opportunity to speak English as much as possible in the classroom. 
Gardener to flowers, watering, fertilization, but also give them "pruning", "modeling", they are in accordance with the gardener's own aesthetic standards the flowers out of shape for people to enjoy. In the gardener seems not to their own taste of the "crooked branches", "disabled" is a "sentenced to death", they can be free "pruning", you can cultivate a song for the United States, "the disease may". However, the teachers and students life homology, teachers should permit the existence of the shortcomings of the students should be allowed for the wizards, bias, geeks, mad to the development. Teachers should be to guide the growth of the students, to the students of the life oriented, rather than limiting their development space, not to give refused to accept the discipline of their students or some defects of students "sentenced to death". Teachers should be more loving, some of the "problem students" understanding and caring, the shortcomings of the students as wealth and teaching, because it may make you a educator -- without any a educator not because the education of problem students succeed and become a true educator.

\section{Two, assessment (assessor)}

The main part of the teacher's work is to assess the student's learning, so as to know their learning and progress, so as to adjust their teaching to adapt to the students. This is not only the need of teaching, but also the urgent desire of the students. There are two ways of assessing: correcting errors and organizing feedback (feedback) (Harmer, 1991).

Correct the error should pay attention to select the appropriate time and attention to artistic, must not be every mistake will be corrected, or in order to correct the mistakes and interrupt the student speech, because that would hit the students enthusiasm for learning so that they can not speak English. Teachers can repeat the words of the students to correct the error, so that not only save the students' face, but also enable students to learn the correct sentence in the middle of the correct sentence. In addition, the teacher should be in time for each student's efforts to be publicly praised and affirmed in order to maintain their enthusiasm for learning.

Organizational feedback (feedback) is a teacher's overall evaluation of the students after they have completed a task. Teachers should be sure of the advantages and points out the problems and how to solve these problems in the future. For example: new materials for each unit of research project, the students grouped do some research to complete a theme, and make courseware, finally by each group in the class of performance report (presentation).

I use of English learning and growth record folder, each finish teaching a unit. Ask the students to in accordance with the unit teaching aims and demands, check and fill in the corresponding unit learning summary (students usually learning performance), unit of study analysis of the summary (the learning enthusiasm and initiative, the main achievement of learning and communication with the students to discuss the experience of what problems exist), feedback learning, teachers need to help further problems and to the teacher's teaching suggestions), analyze and summarize the parents evaluation and opinion, and unit test. Arrange the class representative to fill in the test (homework) score sheet. The teacher carefully read each student's summary and the student's unit of study and summary gives the corresponding comments and suggestions, in a timely manner to encourage students to solve the difficult problems of students. By using the above record holder, the students are evaluated, and the evaluation method of the hero is changed, which is based on the evaluation of the test results (i.e., the final evaluation)[3].

\section{Three, the organizers (organizer)}

The organizer is the most difficult and important role of the teacher, the success of the classroom activity depends on the teacher's organization (Harmer, 1991). Teachers must send out accurate and comprehensive instructions before they can finish any tasks, so that students can know exactly what they are going to do. I heard a lot of lessons and activities for the students who are not successful is because the teacher did not give a clear key instruction, students do not know what, or because of poor English do not know how to carry on the conversation or discussion, make the classroom silence, many students participate in sports or in Chinese conversation, and waste a lot of valuable 
class time. Special attention should be paid to: the teacher can not take it for granted that students know how to do it. Before the whole class, it is necessary to carry out the demonstration of teachers and students. Can also check some of the students to check whether they have mastered. In addition, in order to make the students understand, when necessary, can use chinese. Therefore, the teacher in preparing lessons, to spend a certain amount of time thinking about how to give instructions, in order to enable students to clear. Unfortunately, at present very few teachers to study this point, and to give sufficient attention.

A new round of curriculum reform of basic education theory is the growing point of "comprehensive practical activities", the core of comprehensive practice is "inquiry learning". One of the goals of curriculum reform is to promote the students to change the way of learning. From passive learning to active inquiry learning. To achieve this change, in addition to change teaching evaluation mode, also must promote teachers' role change. Come out from the traditional, deal with the relationship between "inheritance" and "development", should guide teachers gradually realize the following changes:

We should be allowed in certain areas of knowledge do not understand the problem rather than the absolute authority. Teachers can learn from the students, to students admit that they do not understand the problem, can ask the students to help the teacher solve teaching problems, let students eliminate the mystery of learning "". Teachers should not pose as by "the authority of knowledge", and should with the student establish an equal relationship between teachers and students, so that students feel that learning is a kind of equal exchange, is a kind of enjoyment, is a life's calling.

Teachers should become a facilitator of learning, not just a guide, to become "holding students to go" to "push the students to go, to change" to the student pressure "is" to motivate the students "with encouragement, encourage, appreciate the means of the students take the initiative to promote the development of.

We advocate the expert teacher, but does not advocate the teacher standing in the height of students experts. Teachers should have the courage to become a willing pupil, and students build the classroom, and students learning together, happy together to share together, grow together. Teachers should not only become a student teacher, but also to become a student alumni.

For a long time, the teachers have been compared to the engineer of the human soul ". In fact, teachers should not be the students of the soul of the designers, and students should be the soul of the casting, purification. Teachers should be students "mental arousal" rather than "the soul of the default", to become a student's "spiritual coach".

\section{Four, participants (participant)}

"Participant" is the teacher to the students as a member of their participation in various activities. In student activities, teachers can not only station on the podium wait-and-see, and should continue to actively participate in group activities, because it not only can improve the classroom atmosphere, for students to provide level and English better than they say English opportunities (Harmer, 1991). And can enhance the feelings between teachers and students. At the same time, the teacher in the participation in the process can help students solve problems, can also learn many of their unexpected good ideas to the students[4], in favor of my own teaching in the future, enabling students to learn from each other, teaching benefits teachers as well as students. The problem is that, when the teacher is involved, it is easy to control the activities of students, so teachers should pay special attention to let the students become the master of the activities.

We have recognized teachers to teach to the students a bowl of water must have a bucket of water. However, with the changes of the times, in the era of knowledge economy has come, original teachers in a bucket of water may have become obsolete, which requires knowledge of teachers with the changes of the times and constantly updated, teachers need to become the "endless Ben River", teachers should guide students to "cut spring of mining to explore, to find the knowledge of the oasis.

In the new class, it is not only a teacher to ask a series of questions for the students to solve the 
problem. It requires teachers to guide students to ask questions, because it is more important to ask questions than to solve problems. The student asked the teacher the question, then is the challenge to the teacher. Open classroom teachers may accept student challenges, and become the challenger.

China's traditional culture the teacher compared to "spring silkworm", "candles", regardless of is spring or a candle always in the dedication to the object at the same time and destroy body away. A new era of teachers are not to make "silkworm" or "candles" and should be in dedication to the society and to constantly replenish nutrition, become evergreen fruit trees "," rather than in illuminating the world or spit Fang silk after destroy themselves.

Teachers can not take the classroom as their own classroom, and should be returned to the students. A teacher can't be the ruler of a class, because the ruler is always inevitable ". Teachers should go down from the rule of the "altar", and students. In the new curriculum teacher cannot again is condescending, but with the students stand on the same platform interactive exploration, "the referee" in the equal exchange, "chief" in the heated debate.

The gardener is respectable. But "gardener" is regrettable, because the gardener put flowers as "offbeat life". Gardener to flowers, watering, fertilization, but also give them "pruning", "modeling", they are in accordance with the gardener's own aesthetic standards the flowers out of shape for people to enjoy. In the gardener seems not to their own taste of the "crooked branches", "disabled" is a "sentenced to death", they can be free "pruning", you can cultivate a song for the United States, "the disease may". However, the teachers and students life homology, teachers should permit the existence of the shortcomings of the students should be allowed for the wizards, bias, geeks, mad to the development. Teachers should be to guide the growth of the students, to the students of the life oriented, rather than limiting their development space, not to give refused to accept the discipline of their students or some defects of students "sentenced to death". Teachers should be more loving, some of the "problem students" understanding and caring, the shortcomings of the students as wealth and teaching, because it may make you a educator -- without any a educator not because the education of problem students succeed and become a true educator.

\section{Five, mentor or coach (tutor)}

"Mentor or coach" means a student who is on a mission to teach or independently complete the tasks they have chosen, and the teacher guides them or makes recommendations (Harmer, 1991).

This role is especially important in improving the students' writing level and doing research, because the teacher points out the mistakes and the suggestions for improvement are the key to the successful completion of the task[5].

\section{Conclusion}

To be a good facilitator, teachers must strictly grasp "let go" and "control". Do the "let go" when "let go"". Control of the "control"". Special importance in letting go, so that students can also feel the teacher's control". This requires the teacher usually strict requirements for students. More importantly, the ability of the teacher must have extensive knowledge and encourage students to persuade. At the same time, teachers must have a strong sense of responsibility, words and deeds, often to the students were patient and painstaking ideological and moral education.

In order to encourage students to learn and stimulate their learning motivation, each lesson I have any efforts for students timely praise and recognition, at the same time, pay attention to the use of appropriate and different vocabulary and language (such as: "that is a good and new point." "you are very brave!" "you guessed exactly!" "you have made progress and I am so proud of you!"), to avoid a thousand times shall be empty "very good!". After each exam, I buy a notebook for students and the progress of the first students to reward, and in the notebook first page write incentive of discourse; after each research, I used the same method recognition and reward outstanding students. Each essay, choose good writing, posted on the back of the classroom. 


\section{References}

[1] HolecH.Aw/onomyinForeignLangLearning[M].Oxford: Pergamon1981.

[2] Li\tleD.LearningAutonomy 1:Definitions, IssusandProblems[M].Dublin: Authentic1991.

[3]BensonP.ConceptsofAutonomyinLanguageLearning[A].R.Pemberton(ed.)TakingControl: AutonomyinLanguageLearn-ing[C].HongKong: HongKongLniversitvPress 1996.

[4] Department of higher education of the Ministry of education. College English Curriculum Requirements (for Trial Implementation) M]. Beijing: Higher Education Press, 2004:8.

[5] Li Xia. Based on the constructivism theory to design the College English Network Courseware

[J]. China audio visual education, 2004 (10). 